\title{
The Origin of Life-Did It Occur at High Temperatures?
}

\author{
Stanley L. Miller, ${ }^{1}$ Antonio Lazcano ${ }^{2}$ \\ ${ }^{1}$ Department of Chemistry and Biochemistry, University of California, San Diego, La Jolla, CA 92093-0317, USA \\ ${ }^{2}$ Departamento de Biologi'a, Facultad de Ciencias, UNAM, Apdo. Postal 70-407, Cd. Universitaria, México 04510, D.F., Mexico
}

Received: 10 June 1995 / Accepted: 31 July 1995

\begin{abstract}
A high-temperature origin of life has been proposed, largely for the reason that the hyperthermophiles are claimed to be the last common ancestor of modern organisms. Even if they are the oldest extant organisms, which is in dispute, their existence can say nothing about the temperatures of the origin of life, the RNA world, and organisms preceding the hyperthermophiles. There is no geological evidence for the physical setting of the origin of life because there are no unmetamorphosed rocks from that period. Prebiotic chemistry points to a low-temperature origin because most biochemicals decompose rather rapidly at temperatures of $100^{\circ} \mathrm{C}$ (e.g., half-lives are $73 \mathrm{~min}$ for ribose, 21 days for cytosine, and 204 days for adenine). Hyperthermophiles may appear at the base of some phylogenetic trees because they outcompeted the mesophiles when they adapted to lower temperatures, possibly due to enhanced production of heat-shock proteins.
\end{abstract}

Key words: Origin of life - Hyperthermophiles Heat shock proteins - Submarine hydrothermal vents - Pre-RNA world - RNA world - Primitive atmosphere

\section{Introduction}

Although considerable efforts have been made to understand the emergence of the first living systems, we still do not know when and how life originated. Since it is

Correspondence to: S.L. Miller sometimes possible to correlate major evolutionary changes with environmental conditions, several attempts have been made to infer the conditions in which life arose by studying the oldest known organisms. As summarized by Pace (1991), molecular evolution analysis has suggested that the oldest recognizable prokaryotes are the anaerobic sulfur-reducing chemosynthetic hyperthermophiles, i.e., organisms that grow optimally at $90^{\circ} \mathrm{C}$ and above. This observation has been interpreted to imply that the first living systems may have originated in a high-temperature environment, such as those found today in deep-sea hydrothermal vents (Holm 1992) although terrestrial hot springs would be equally consistent. This is a simple extrapolation of the growth temperature of extant hyperthermophiles to the origin of life (Fig. 1, dotted line tree). There is no more justification for this extrapolation than for a mesophilic origin (Fig. 1, solid line tree) or an even higher temperature origin (not shown).

\section{How Old Are the Hyperthermophiles?}

A thermophilic origin of life is not a new idea. It was first suggested by Harvey (1924) that the first forms of life were heterotrophic thermophiles that had originated in hot springs. The antiquity of hyperthermophiles is now widely accepted not only for archaebacteria but also for the less well-known eubacterial extremophiles (Stetter 1994). However, alternative opinions have developed since Pace's article in 1991. For example, the archaea may not be the oldest lineage (Doolittle 1995), and there are some indications for separation of the three domains as late as $2 \times 10^{9}$ years ago (Doolittle et al., 1996). In 


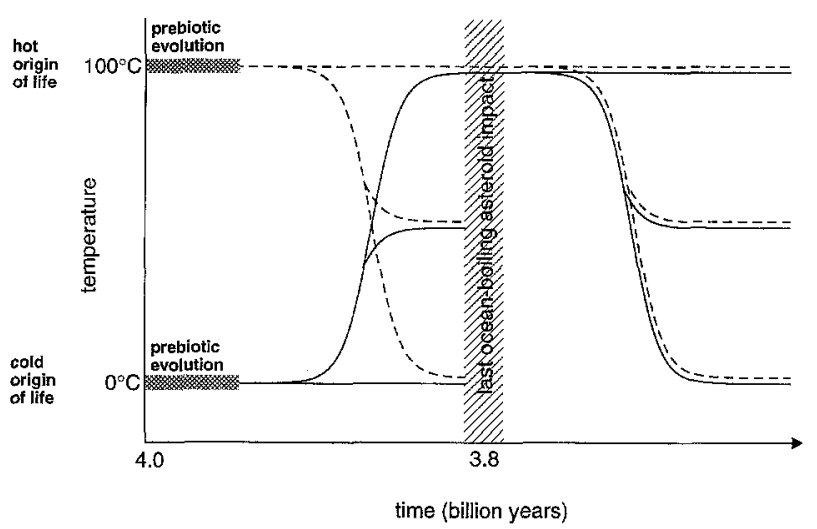

Fig. 1. Some alternative temperature regimes for the origin and early evolution of life. The dotted line shows a hot origin of life followed by adaptation to several lower temperatures. Only the hyperthermophiles would survive the last asteroid impact which boiled the ocean. The solid line shows a low temperature origin of life followed by adaption to higher temperatures, with survival of only the secondarily adapted hyperthermophiles after the asteroid collision. Not shown are earlier collisions that may have frustrated the origin of life or its survival.

addition, some hyperthermophile sequences are displaced from their basal position if molecular markers other than elongation factors or ATPase subunits are employed (Forterre et al. 1993; Klenk et al. 1994), i.e., other molecular trees also open up the possibility that the last common ancestor of all living beings was not a thermophilic prokaryote. It could be argued that the discovery of frigid archaea living in Antarctic waters (DeLong et al. 1994) supports a low-temperature origin of life, but the same considerations of Fig. 1 apply to these organisms. Thus, the base of the tree at $0^{\circ}$ would correspond to the growth conditions of low-temperature archaea $\left(-5^{\circ} \mathrm{C}\right.$, instead of 100 to $110^{\circ} \mathrm{C}$ ).

\section{Hyperthermophiles May Be Ancient, But They Are Hardly Primitive}

It is important to distinguish between ancient and primitive. Hyperthermophiles may be cladistically ancient, but they are hardly primitive relative to the first living organisms. In fact, they seem to be no more primitive in their metabolic apparatus than mesophiles (Adams 1993). For example, biosynthesis of arginine in Thermotoga maritima appears to be essentially the same as in all known organisms (Van de Casteele et al. 1990), and tryptophan biosynthetic genes in the thermoacidophile Sulfolobus solfataricus are homologous to their mesophilic eubacterial and eukaryotic counterparts (Tutino et al. 1993).

Primitive living systems, according to some current opinion, would initially refer to the pre-RNA world, in which life was first based on polymers using backbones other than ribose-phosphate and possibly bases different from AUGC. This was followed by a stage in which life was based on RNA as both the genetic material and as catalysts. The RNA world was followed by a DNA/ protein world with rather limited biosynthetic capabilities, and in the subsequent stages of biological evolution, the basic characteristics of metabolic pathways were established. In view of this enormous metabolic development, a constant-temperature extrapolation is hardly justified. These considerations apply if the alternative hypothesis is correct that mesophiles are the most ancient, as suggested by some phylogenetic trees. In this case, constant-temperature extrapolation points to a lowtemperature origin of life, but a high-temperature regime or a colder one are equally justified (Fig. 1).

The antiquity of hyperthermophiles fits in with the plausible hypothesis of impact frustration of the origin of life (Maher and Stevenson 1988; Sleep et al. 1989), for which, however, there is no geological evidence. If the last large asteroid to hit the Earth was $400 \mathrm{~km}$ in diameter or larger it would have converted the entire ocean to steam. This would have killed off most organisms but the hyperthermophiles would have been selected for, therefore explaining their basal position in some phylogenetic trees. Such extreme thermophiles are sometimes said to be submarine vent organisms (Gogarten-Boekels et al. 1995), but any hyperthermophile would have survived.

It should be kept in mind that even if the whole ocean boils, there may be areas where the temperature is not raised, or where the organisms are protected, e.g., several kilometers deep in marine and continental sediments. Since a boiling ocean would cool in $\sim 1,000$ years, the high temperatures would not reach the organisms this deep. Prokaryotic biotas are found today at depths of 0.5 $\mathrm{km}$ or more in the oceanic sediments (Parkes et al. 1994), and if such communities were present at the last impact, it is reasonable to think that they would have survived.

\section{What Was the Physical Setting of the Origin of Life?}

Many strong statements have been made about the primitive Earth, but there is no direct geological evidence for any of these hypotheses, since there are no rocks older than $3.8 \times 10^{9}$ years. Calculations of atmospheric and planetary formation models, however meritorious, do not constitute evidence.

The temperature of the primitive Earth during the period of the origin of life is unknown. The entire planet is generally thought, without direct evidence, to have remained molten for several hundred million years after its formation $4.6 \times 10^{9}$ years ago (Wetherill 1990). The oldest sedimentary rocks in the Greenland Isua formation have been heated to $500^{\circ} \mathrm{C}$, so the evidence on the conditions at that time has been largely destroyed. The sediments in the Australian Warrawoona formation $3.5 \times$ $10^{9}$ years old contain very convincing cyanobacteria-like microfossils (Schopf 1993).

Thus, life is thought to have originated some time 
between 4.0 and 3.5 billion years ago, but there is no direct evidence for the temperature or atmospheric conditions. Some atmospheric models incorporate high partial pressures of $\mathrm{CO}_{2}$ to raise the temperature of the Earth by a greenhouse effect and thus prevent the complete freezing of the oceans (Kasting 1993). However, a frozen Earth has some advantages for prebiotic chemistry (Bada et al. 1994). But again, there is no direct evidence either way. In addition, processes relevant to the origin of life may have taken place in environments different from the terrestrial average, e.g., hot springs, eutectic sea water, or drying lagoons.

The composition of the atmosphere poses a similar problem: there is no geological evidence as to whether the Earth's atmosphere was reducing or nonreducing, although it is generally accepted that $\mathrm{O}_{2}$ was absent. It is beyond the scope of this review to explore this question, except to comment that atmospheric chemists mostly favor high $\mathrm{CO}_{2}+\mathrm{N}_{2}$, whereas prebiotic chemists mostly favor more reducing conditions $\left(\mathrm{CH}_{4}+\mathrm{N}_{2}\right.$ or $\mathrm{CO}_{2}+\mathrm{H}_{2}$ $+\mathrm{N}_{2}$ ). Reducing conditions are required for the synthesis of amino acids, purines, pyrimidines, and sugars, and such syntheses are very efficient (Stribling and Miller 1987). The robustness of this type of chemistry is supported by the occurrence of most of these biochemical compounds in the Murchison meteorite, which comes from an asteroid. The meteorite analysis results make it plausible, but do not prove, that such syntheses also occurred on the primitive Earth. Based on what is known about prebiotic chemistry, if the Earth was not reducing, then the organic compounds would have to be brought to it by dust particles, comets, and meteorites (Anders 1989; Chyba et al. 1990). The amounts that can be brought in this way and survive passage through the atmosphere are quite small, and may not have been sufficient for the origin of life.

\section{High Temperatures Give Higher Reaction Rates, But There Is a Price to Pay}

The one advantage of high temperatures is that the chemical reactions could go faster and the primitive enzymes could have been less efficient (Harvey 1924), but the price paid is loss of organic compounds by decomposition and diminished stability of the genetic material. The problem with monomers is bad enough, but it is worse with polymers, e.g., RNA and DNA (Lindahl 1993), whose stability in the absence of efficient repair enzymes is too low to maintain genetic integrity in hyperthermophiles. RNA and DNA are clearly too unstable to exist in a hot prebiotic environment. The existence of an RNA world with ribose appears to be incompatible with the idea of a hot origin of life. The stability of ribose and other sugars is the worst problem, but pyrimidines and purines and some amino acids are nearly as bad. The half-life of ribose at $100^{\circ} \mathrm{C}$, and $\mathrm{pH} 7$ is only $73 \mathrm{~min}$, and other sugars have comparable half-lives (Larralde et al. 1995). The half-life for deamination of cytosine at $100^{\circ} \mathrm{C}$ is 21 days (Garrett and Tsau 1972; Shapiro and Klein 1966 ), and 204 days at $100^{\circ} \mathrm{C}$ for adenine (Frick et al. 1987; Shapiro 1995). Some amino acids are stable, e.g., alanine with a half-life for decarboxylation of approximately 19,000 years at $100^{\circ} \mathrm{C}$, but serine decarboxylates to ethanolamine with a half-life of 320 days (Vallentyne 1964), with dealdolization and dehydration as additional decomposition routes (Bada et al. 1995). Similar considerations show that the growth of organisms at $250^{\circ} \mathrm{C}$ or $350^{\circ} \mathrm{C}$ and the origin of life at such temperatures (Corliss et al. 1981) are very unlikely (White 1984; Miller and Bada 1988). It is clear that if the origin of life took place at $100^{\circ} \mathrm{C}$ or higher temperatures, then the organic compounds involved must have been used immediately after their prebiotic synthesis. An alternative is to assume an autotrophic origin of life, i.e., the first organisms made all their cell material from $\mathrm{CO}_{2}, \mathrm{~N}_{2}$, and $\mathrm{H}_{2} \mathrm{O}$. Proposals of an autotrophic origin of life are periodically resurrected, but they are made without supporting experiments.

\section{Hyperthermophily May Be a Secondary Adaptation?}

An analysis of the rooted tree provided by Stetter (1994) suggests to us a polyphyletic origin of mesophiles from hyperthermophiles, i.e., an independent, parallel abandonment of hyperthermophilic traits has taken place in widely separated branches of the universal tree. This could suggest that relatively few genetic changes may be required to abandon a thermophilic lifestyle. However, other rootings of universal trees permit the evolution of mesophilic branches into hyperthermophilic ones (Rivera and Lake 1992; Klenk et al. 1994; Forterre et al. 1993).

A possibility that has not been given enough attention is that hyperthermophiles are now at the base of some trees simply because they outcompeted older mesophiles when they adapted to lower temperatures, rather than being the sole survivors of an impact event. Some of the molecular features that are adaptations to hot environments could have enhanced the survival chances of hyperthermophiles and their immediate descendants under less-extreme temperature conditions. An example could be the heat-shock response, whose universal distribution can be interpreted as a remnant of the hyperthermophilic ancestors of extant life. Heat-shock proteins are not only involved in thermotolerance, but also in protection against other stress-inducing agents and environmental insults, including starvation conditions, UV-irradiation, DNA-damaging agents, alcohol, amino acid analogues, etc. (Watson 1990). Accordingly, it is possible to envision that heat-shock genes evolved in ancient hyperthermophiles, preadapting them to other stress-inducing 
conditions at low temperatures, allowing them to successfully outcompete mesophiles. While this scheme may not necessarily be correct, it suggests that additional explanations can be advanced to explain the phylogenetic distribution of hyperthermophiles.

We have addressed the possibility that hyperthermophiles are not the oldest organisms. Even if they are, a straight-line temperature extrapolation back in time to the origin of life is not warranted. Prebiotic chemistry points toward a low-temperature regime for the emergence of living systems. If this conclusion is valid, it merits a search for mesophiles older than hyperthermophiles.

Acknowledgments. We thank Jason P. Dworkin and Jeffrey Bada for helpful comments. Support was provided by the NSCORT (NASA Specialized Center for Research and Training) in Exobiology at the University of California, San Diego.

\section{References}

Adams MWW (1993) Enzymes and proteins from organisms that grow near and above $100^{\circ} \mathrm{C}$. Annu Rev Microbiol 47:627-658

Anders E (1989) Pre-biotic organic matter from comets and asteroids. Nature 342:255-257

Bada JL, Bigham C, Miller SL (1994) Impact melting of frozen oceans on the early Earth: implications for the origin of life. Proc Natl Acad Sci USA 91:1248-1250

Bada JL, Miller SL, Zhao M (1995) The stability of amino acids at submarine hydrothermal vent temperatures. Orig Life Evol Biosph 25:111-118

Chyba CF, Thomas PJ, Brookshaw L, Sagan C (1990) Cometary delivery of organic molecules to the early Earth. Science 249:366-373

Corliss, JB, Baross JA, Hoffman SE (1981) An hypothesis concerning the relationship between submarine hot springs and the origin of life on Earth. Oceanocogica Acta 4, Suppl 59-69

DeLong EF, Wu KY, Prézelin BB, Jovine RVM (1994) High abundance of Archaea in Antartic marine picoplankton. Nature 371: 695-697

Doolittle RF (1995) Of Archae and Eo: what's in a name? Proc Natl Acad Sci USA 92:2421-2423

Doolittle RF, Feng DF, Tsang S, Cho G, Little E (1996) Determining the divergence times of the major kingdoms of living organisms with a protein clock. Science (submitted)

Forterre P, Benachenhou-Lahfa N, Confalonieri F, Duguet M, Elie Ch, Labedan B (1993) The nature of the last universal ancestor and the root of the tree of life, still open questions. Biosystems 28:15-32

Frick L, Mac Neela JP, Wolfenden R (1987) Transition state stabilization by deaminases: rates of nonenzymatic hydrolysis of adenosine and cytidine. Bioorg Chem 15:100-108

Garrett ER, Tsau J (1972) Solvolyses of cytosine and cytidine. J Pharm Sci 61:1052-1061

Gogarten-Boekels M, Hilario E, Gogarten JP (1995) The effects of heavy meteoritic bombardment on the early evolution - the emer- gence of the three domains of life. Orig Life Evol Biosph 25:251264

Harvey RB (1924) Enzymes of thermal algae. Science 60:481-482

Holm NG ed (1992) Marine hydrothermal systems and the origin of life. Klüwer, Academic, Dordrecht. 242 pp. Also a special issue of Origins of Life and Evolution of the Biosphere 22:1-241

Kasting JF (1993) Earth's earliest atmosphere. Science 259:920-926

Klenk HP, Palm P, Zillig W (1994) DNA-dependent RNA polymerases as phylogenetic marker molecules. Syst Appl Microbiol 16:638647

Larralde R, Robertson MP, Miller SL (1995) Rates of decomposition of ribose and other sugars: implications for chemical evolution. Proc Natl Acad Sci USA 92:8158-8160

Lindahl T (1993) Instability and decay of the primary structure of DNA. Nature 362:709-715

Maher KA, Stevenson DJ (1988) Impact frustration of the origin of life. Nature 331:612-614

Miller SL, Bada JL (1988) Submarine hot springs and the origin of life. Nature 334:609-611

Pace NR (1991) Origin of life-facing up to the physical setting. Cell 65:531-533

Parkes RJ, Cragg BA, Bale SJ, Getliff JM, Goodman K, Rochelle FA, Fry JC, Weightman AJ, Harvey SM (1994) Deep bacterial biosphere in Pacific Ocean sediments. Nature 371:410-413

Rivera MC, Lake JA (1992) Evidence that eukaryotes and eocyte prokaryotes are immediate relatives. Science $257: 74-75$

Shapiro R (1995) The prebiotic role of adenine: a critical analysis. Orig Life Evol Biosph 25:83-98

Shapiro R, Klein RS (1966) The deamination of cytidine and cytosine by acidic buffer solutions. Mutagenic implications. Biochemistry 5:2358-2362

Schopf JW (1993) Microfossils of the early Archean Apex chert: new evidence of the antiquity of life. Science 260:640-646

Sleep NH, Zahnle KJ, Kasting JF, Morowitz HJ (1989) Annihilation of ecosystems by large asteroid impacts on the early Earth. Nature 342:139-142

Stetter KO (1994) The lesson of archaebacteria. In: Bengtson S. (ed) Early life on earth: Nobel symposium No. 84. Columbia University Press, New York, pp 114-122

Stribling R, Miller SL (1987) Energy yields for hydrogen cyanide and formaldehyde synthesis: the HCN and amino acid concentrations in the primitive oceans. Orig Life Evol Biosph 17:261-273

Tutino ML, Scarano G, Marino G, Sannia G, Cubellis MV (1993) Tryptophan biosynthesis genes $\operatorname{trpEGC}$ in the thermoacidophilic archaebacterium Sulfolobus solfataricus. J Bacteriol 175:299-302

Vallentyne JR (1964) Biogeochemistry of organic matter II: thermal reaction kinetics and transformation products of amino compounds. Geochim Cosmochem Acta 28:157-188

Van de Casteele M, Demarez M, Legrain C, Glansdorff N, Pierard A (1990) Pathways of arginine biosynthesis in extreme thermophilic archaebacteria and eubacteria. J Gen Microbiol 136:1177-1183

Watson K (1990) Microbial stress proteins. Adv Microbiol Physiol 31:183-223

Wetherill GW (1990) Formation of the Earth. Annu Rev Earth Planet Sci 18:205-256

White RH (1984) Hydrolytic stability of biomolecules at high temperatures and its implication for life at $250^{\circ} \mathrm{C}$. Nature $310: 430-432$ 